\title{
Altruistic versus Profit Maximising System Operators of Rural Power Systems
}

\author{
A. Sendegeya \\ Electrical Engineering Department, Faculty of Technology, Makerere University, P. O. Box 7062 Kampala, Uganda, Phone: \\ +256-712-239626, Fax: +256-41-532008, Email: a_sendegeya@tech.mak.ac.ug, a PhD student at the Royal Institute of \\ Technology (KTH), Sweden, Phone: +46 8-790 7750, Fax: +46 8790 6510, Email: al-mas.sendegeya@ee.kth.se \\ M. Amelin and L. Söder \\ Electric Power Systems Lab, School of Electrical Engineering, Royal Institute of Technology (KTH), Teknikringen 33 KTH, \\ S-100 44 Stockholm, Sweden, Phone: +46 8-790 7755, Fax: +46 8790 6510, Email: mikael.amelin@ee.kth.se and \\ lennart.soder@ee.kth.se \\ E. Lugujjo and I. P. Da Silva \\ Electrical Engineering Department, Faculty of Technology, Makerere University, P. O. Box 7062 Kampala, Uganda, Phone: \\ +256-41-505792, Fax: +256-41-532008, Email: elugujjo@tech.mak.ac.ug and idasilva@tech.mak.ac.ug
}

\begin{abstract}
This paper presents a methodology using Monte Carlo Simulation for analysing and compare the impact of two types of monopolistic rural power system operators (altruistic and profit maximising operators) on the probability distribution of tariff levels and reliability of the system. The market has price sensitive consumers. The developed model has been demonstrated on two power systems: only diesel genset and a wind-diesel hybrid system showing the impact of the generation costs and capacity of generation from wind on the tariff levels, expected profit and reliability.
\end{abstract}

Index Terms - altruistic, profit maximisation, price sensitivity, rural power systems

\section{INTRODUCTION}

Provision of reliable and affordable electric services to the rural communities of developing countries is among the challenging aspects currently faced by researchers and policy makers. Depending on the number, size and location or distribution of most rural consumers, rural power systems may be attractive to individual operators to manage both the generation and distribution. Due to the high initial costs required to develop the available resources the operation of rural power systems may demand local monopolists. These monopolies in most cases are under state regulation [1]. These could be private companies, cooperatives (usually group of farmers), government owned companies and nongovernmental organisations (NGOs). The ultimate objective of private companies is to maximise profit. These companies have been referred to as profit maximising system operators. Government owned companies, cooperatives and NGOs in most cases aim at extending affordable services and improve the well-being of the target community. In other words the later operate to ensure that the cost of the service is as cheap as possible just focusing on the sustainability of the system. Such operators have been referred to as altruistic system operators.

Due to the low economic levels and availability of cheap competing energy options, electricity consumers in rural communities are considered to be sensitive to changes in tariff. The consumer price sensitivity depends on the economic situation of individual consumers and the society as a whole. Probability simulation methods have been suggested in this work that can be used for this kind of electricity markets with price sensitive consumers. Probability methods have been used in various studies, for example in the investigation of oligopoly and perfect competition markets [2]. Also investigations of electricity markets with price sensitive consumers have been presented under different market situations [2], [3] [4]. Although the previous works have addressed the behaviour of large electricity markets with price sensitive consumers, there is still a need to investigate how operators of small rural power systems will adopt their tariffs to the consumer price sensitivity.

This paper describes a simulation method for rural electricity markets dominated by price sensitive consumers, whereby power supplied optionally by two types of operators; altruistic and profit maximising operators. The tariff levels and other system parameters are compared and uniquely presented with a method for estimating price duration curves. A methodology using Monte Carlo simulation has been presented to compare tariff levels for the two types of operators under the same market environment. The price sensitivity of consumers is explicitly described by a known probability distribution.

\section{THE MODEL}

An isolated rural power system has been modeled with price-sensitive demand and hybrid generation (diesel generator sets and wind turbines).

\section{A. Load}

The load at a specific time, $D(t)$ is assumed to be a product of the peak demand, $D_{P}$, and relative load $D^{r e l}$, as given in (1). 


$$
D(t)=D_{P} \times D^{r e l}
$$

The peak demand is a function of tariff and the relative load is assumed to be a random variable. Mathematically, consumers' response to changes in price can be represented by one of the three demand functions distinguished as linear, Cobb-Douglas and constant price-sensitive [1], [2], [3]. The mathematical simplicity of the linear function makes it theoretically attractive compared to the rest. Thus, the relation between peak-demand and tariff is expressed in (2).

$$
D_{P}=f(\lambda)=\frac{\alpha-\lambda}{\beta}
$$

where $\alpha$ and $\beta$ are the demand factor and sensitivity respectively. These parameter (herein referred to as market parameters) are assumed to be random variables with known probability distributions, which constitute inputs to the simulation.

The relative load is continuously varying. For example, the relative load of an isolated rural power system is typically low during the night and during the day, but will be closer to the peak demand during the evenings. In this model, the relative load is simply represented by known probability distribution, which also constitutes an input to the simulation. Thus, the load at an instant is a random variable that depends on the probability distributions of both market parameters and relative load.

\section{B. Generation}

The generation consists of thermal and wind power plants. The thermal power plant is characterised by rated capacity, availability of generation, and generation cost, which is assumed to be constant in the simulation. The simplest model of the plant is a discrete two states model: either available or not available [7]. A thermal generation plant comprising $n$ sets, its total generation is in $2^{n}$ states and the generation cost depends on demand and available units.

Wind power is characterised by the generation at a given wind speed, availability and operation costs. The generation is modelled as a probability distribution for the available generation capacity at a given wind speed which in most cases assumed to follow a Rayleigh distribution [7], [8]. The available generation is a random variable with the probability density obtained by combining the probability distribution of wind speed and the inverse of the generation capacity function.

\section{Concepts of operators}

The reference parameter considered for the two types of power system operators is profit. The conceptual explanation and understanding of these operators is demonstrated using profit versus tariff curve as in figure 3 .

If the company would be providing power for free (point $X$ in the figure, i.e. Profit $<0$ ) then it would make a loss, as it can recover neither operation costs nor fixed costs. Imposing a tariff to consumers reduces the financial loss until a break even point is attained at tariff, $\lambda_{0}$ (point $Y$ ), i.e., when the operator makes neither a profit nor a loss, Profit $=0$. An operator that sells power at this tariff is just ensuring economic sustainability of the power system and does not make profit (have been referred to as an altruistic system operators). An increase in tariff beyond an altruistic tariff, $\lambda_{0}$ leads to an increase in profit until the maximal profit, Profit $_{O P T}$ is attained at tariff, $\lambda_{O P T}$ (point $Z$ ). An operator delivering power at point $Z$ has been referred to as profit maximising system operator.

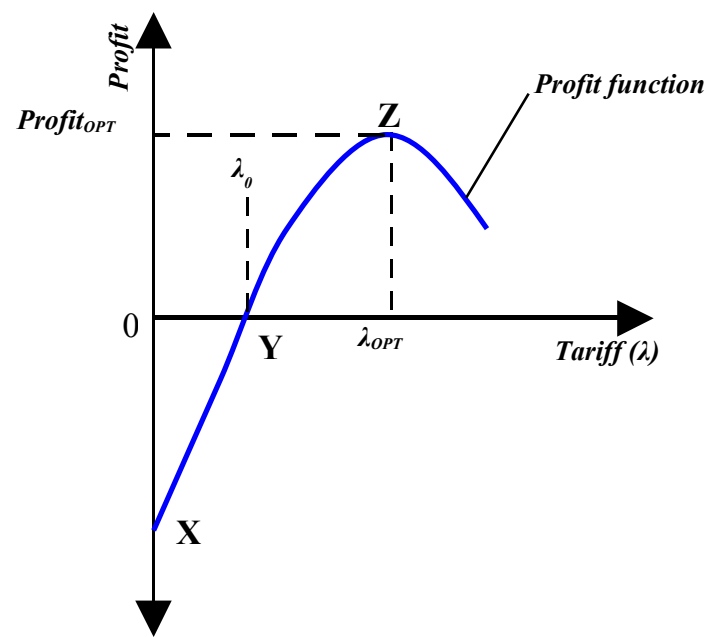

Fig.1. Profit Curve demonstrating altruistic and profit maximisation concepts at tariffs, $\lambda_{0}$ and $\lambda_{O P T}$ respectively

\section{SIMULATION PROCEDURE}

As described in section II, the consumer price sensitivity is represented by random variables. The assumption taken is that the system operators have perfect information about the market. This means that the operators at every time set the tariff of the system so that the expected profit is maximised (profit maximizing operator) or that the expected revenue equal to expected cost (altruistic operator). The simulation method used consists of two levels of Monte Carlo simulation; the main simulation (referred to as outer Monte Carlo simulation) and the sub-simulations (referred to as inner Monte Carlo simulation). The objective of the main simulation is to determine the probability distribution of tariff and loss of load probability for both profit maximizing and altruistic system operators, and expected profit for profit maximizing system operators. Each generated sample of the outer Monte Carlo simulation requires several calculations of expected costs, expected revenues and loss of load probability. These calculations are performed in the inner Mont Carlo simulation. 
The simulation procedure is based on the principle of correlated sampling to increase the accuracy of the comparison between the two operators in the outer Monte Carlo simulation. For each random set of inputs, demand factor $(\alpha)$ and consumers' price sensitivity $(\beta)$, one set of outputs is generated for a profit maximising operator as well as an altruistic operator and the difference between the two is sampled. In the case of the profit maximising operator, the tariff for a given price sensitivity is calculated using the golden-section search method [9]. The initial interval of the tariff is determined from the sampled demand factor and the golden ration, 0.618 . For each of the calculated tariff limits, the expected operation cost, expected revenue and loss of load probability are determined in the inner Monte Carlo simulation. The search tariff interval is then updated according to the results from the inner Monte Carlo simulation, until point $\mathrm{Z}$ in figure 1 is identified with sufficient tolerance In the case of an altruistic operator, the tariff for a given price sensitivity is calculated using the secant method [9]. The initial interval of the tariff is determined from the tariff for profit maximising operator and the expected lowest price e.g. zero. For each of the calculated tariff limits, the expected operation cost, expected revenue and loss of load probability are determined in the inner Monte Carlo simulation. The search tariff interval is then updated according to the results from the inner Monte Carlo simulation, until point $\mathrm{Y}$ in figure 1 is identified with sufficient tolerance.

\section{A. Simulation Inputs}

The inputs to the simulation include system parameters, probability distributions of consumers' price sensitivity, demand factor, relative load, peak demand and available generation capacity. The system parameters used in the simulation are:

$G_{j}$ : $\quad$ installed capacity of the $j^{\text {th }}$ genset, $j=1,2 \ldots n$ (for $n$ diesel generator sets), [kW]

$C_{G j}$ : $\quad$ generation cost of the $j^{\text {th }}$ genset, [US $\$ / \mathrm{kWh}$ ]

$W_{l}$ : $\quad$ installed capacity of the $l^{\text {th }}$ renewable energy generation plant e.g. wind turbine, $l=1,2 \ldots \mathrm{m}$ (for $m$ plants $),[\mathrm{kW}]$

$C_{W l}$ : generation cost of the $l^{\text {th }}$ renewable energy generation plant [US\$/kWh]

$F C_{q}$ : fixed cost, of $q^{\text {th }}$ generator [US $\left.\$ / \mathrm{h}\right], q=1,2 \ldots \mathrm{n}+\mathrm{m}$

\section{B. The outer Monte Carlo simulation}

A set of sampled inputs and outputs for the outer Monte Carlo simulation is referred to as a case. The inputs and outputs of the different cases are distinguished by the index $\mathrm{k}$. The case parameters are:

$\lambda_{k}: \quad$ the adjusted tariff in the $k^{\text {th }}$ case, [US $\$ / \mathrm{kWh}$ ]

$\beta_{k}$ : $\quad$ price sensitivity for the $k^{\text {th }}$ case (randomized from a probability distribution), [US\$h/ $\mathrm{kWh}^{2}$ ] $\alpha_{k}$ : demand factor for the $k^{\text {th }}$ case (randomized from a probability distribution), [US\$/kWh]

$D_{P k}$ : $\quad$ peak demand in the $k^{\text {th }}$ case, $[\mathrm{kWh} / \mathrm{h}]$, cf. (2).

The outputs of a case are tariff, loss of load probability and the difference in tariff and loss of load probability between the two system operators. For the profit maximising operator, the expected profit is one of the outputs of each case.

\section{The inner Monte Carlo simulation}

A set of inputs and outputs for an inner Monte Carlo simulation is referred to as a scenario. In a scenario it is assumed that the available generation units are dispatched starting with those units with least generation cost. The inputs and outputs of different scenarios are distinguished by index i. The inputs of a scenario (scenario parameters) are:

$D^{r e}{ }_{k, i}$ : relative demand in the $k^{\text {th }}$ case and $i^{\text {th }}$ scenario (randomized from the probability distribution).

$G_{k, i, j}$ : available generation capacity from the $j^{\text {th }}$ generator in $k^{\text {th }}$ case and $i^{\text {th }}$ scenario, $[\mathrm{kWh} / \mathrm{h}]$.

$D_{k, i}$ : demand in $\mathrm{k}^{\text {th }}$ case for $\mathrm{i}^{\text {th }}$ scenario, $[\mathrm{kWh} / \mathrm{h}]$

$D_{k, i}^{*}$ : the supplied load in the $k^{\text {th }}$ case for the $i^{t h}$ scenario $[\mathrm{kWh} / \mathrm{h}], 0 \leq D_{k, i}^{*} \leq D_{k, \mathrm{i}}$, this depends on the available generation

The outputs generated by each scenario:

TOC $_{k, i}$ : total operation costs of the $k^{\text {th }}$ case and $i^{\text {th }}$ scenario, [US\$/h]

$T R C_{k, i}$ : total revenue collection of the $k^{\text {th }}$ case and $i^{\text {th }}$ scenario, [US\$/h]

$L O L O_{k, i}:$ loss of load occurrence of the $k^{\text {th }}$ case and $i^{\text {th }}$ scenario

If the load, $D_{k, i}$ at any moment is greater than the total available generation capacity $\sum G_{k, i, j}$ then the supplied load, $D_{k, i}^{*}=\sum G_{k, i, j}$ and $L O L O_{k, i}=1$. Otherwise $D_{k, i}^{*}=D_{k, i}$ and $L O L O_{k, i}=0 . T O C_{k, i}$ is calculated by multiplying the dispatched generation in each power plant by the corresponding operation cost, and $T R C_{k, i}$ is the product of tariff, and the supplied load, i.e., $T R C k, i=\lambda_{k} . D^{*}{ }_{k, \mathrm{i}}$.

The number of samples in the inner Monte Carlo simulation is either set in advance or can be determined by a convergence criterion. For simplicity, we have assumed that the number of samples is predetermined. Hence, for $N_{S C}$ generated scenarios, the expected performance indices of the system are estimated by calculating averages of the three observed samples: $T O C_{k, \mathrm{i}}, T R C_{k, i}$ and $L O L O_{k, i}$ as in equations (3), (4) and (5).

$$
\begin{aligned}
& E T C_{k}=\frac{1}{N_{S C}} \sum_{i=1}^{N_{S C}} \operatorname{TOC}_{k, i}+\sum_{p=1}^{(n+m)} F C_{p}, \\
& E T R_{k}=\frac{1}{N_{S C}} \sum_{i=1}^{N_{S C}} T_{R C_{k, i}},
\end{aligned}
$$




$$
L O L P_{k}=\frac{1}{N_{S C}} \sum_{i=1}^{N_{S C}} L O L O_{k, i},
$$

For each scenario the expected total profit is obtained as

$$
E T P_{k}=E T C_{k}-E T R_{k},
$$

Where; $E T C_{k}$ : expected total cost, $k^{\text {th }}$ case, [US\$/h]

$E T R_{k}: \quad$ expected total cost, $k^{\text {th }}$ case, [US\$ $\left./ \mathrm{h}\right]$

$E T P_{k}: \quad$ expected total profit, $k^{\text {th }}$ case, [US\$ $/ \mathrm{h}$ ]

$L O L P_{k}$ : loss of load probability, $k^{\text {th }}$ case

\section{Simulation Algorithm}

The algorithm for the complete simulation procedure is summarized in the flow chart in figure 4. Further details are provided in the following pseudo-code:

Step 1.0: Randomize parameters (block B): From the probability distributions of the market parameters; sensitivity, $\beta_{k}$ and demand factor, $\alpha_{\mathrm{k}}$ are randomized for each case.

Step 2.0: Calculate tariff for Profit maximizing operator:

Step 2.1: Set the possible initial range of tariff, $\lambda_{L O W, k} \leq \lambda \leq$ $\lambda_{H I G H, k}$ (block C): The limit is set from the randomized demand factor and the golden factor, 0.618. The lower limit of the tariff range, $\lambda_{L O W, k}$ is set to $(1-0.618) \alpha_{k}=0.382 \alpha_{k}$. The upper limit of the tariff range, $\lambda_{H I G H, k}$ is set to $0.618 \alpha_{\mathrm{k}}$.

Step 2.2: Calculate ETC, ERT and LOLP (block D): The generation and load are randomized for each scenario. Then values of ETC, ERT and LOLP are calculated for $\lambda_{L O W, \mathrm{k}}$ and $\lambda_{H I G H, k}$ in the first inner Monte Carlo simulations.

Step 2.3: Search for maximal profit (blocks E and F): If tariff range is not within the tolerance limits, then use the golden-section search method to update the tariff range limits and go back to step 2.2. The tariff, $\lambda_{O P T, k}$ for $\max \left(E T R_{k}-E T C_{k}\right)$ and the corresponding performance indices, $E T P_{O P T, k}$ and $L O L P_{k}$ (for storage in block K).

Step 3.0: Calculate tariff for Altruistic operator:

Step 3.1: Set the possible initial tariff, $\lambda_{L O W, k} \leq \lambda \leq \lambda_{H I G H, k}$ (block G): The limit is set from the tariff for profit maximising and the lowest possible tariff, taken to be zero.

Step 3.2: Calculate ETC, ERT and LOLP (block E): The generation and load are randomized for each scenario. Then values of ETC, ERT and LOLP are calculated for $\lambda_{L O W, \mathrm{k}}$ and $\lambda_{H I G H, k}$ in the second inner Monte Carlo simulations.

Step 3.3: Search for optimum tariff, $\lambda_{0, k}$ at $E T R_{k} \approx E T C_{k}$, for profit $=0 \quad$ (blocks I and J): If tariff is not within the tolerance limits, then use the secant method to update it and go back to step 3.2. The tariff and the corresponding indices, $L O L P_{0, k}$ (for storage in block $\mathrm{K}$ ).

Step 4.0: Sample the differences in tariffs $\left(\lambda_{O P T, k}\right.$ and $\left.\lambda_{0, k}\right)$, $\operatorname{ETP}\left(E T P_{O P T, k}\right.$ and $\left.E T P_{0, k}\right)$ and LOLP $\left(L O L P_{k}\right.$ and $\left.L O L P_{0, k}\right)$ between profit maximizing and altruistic system operators.

Step 5.0: Check the ending criterion (block $M$ ).

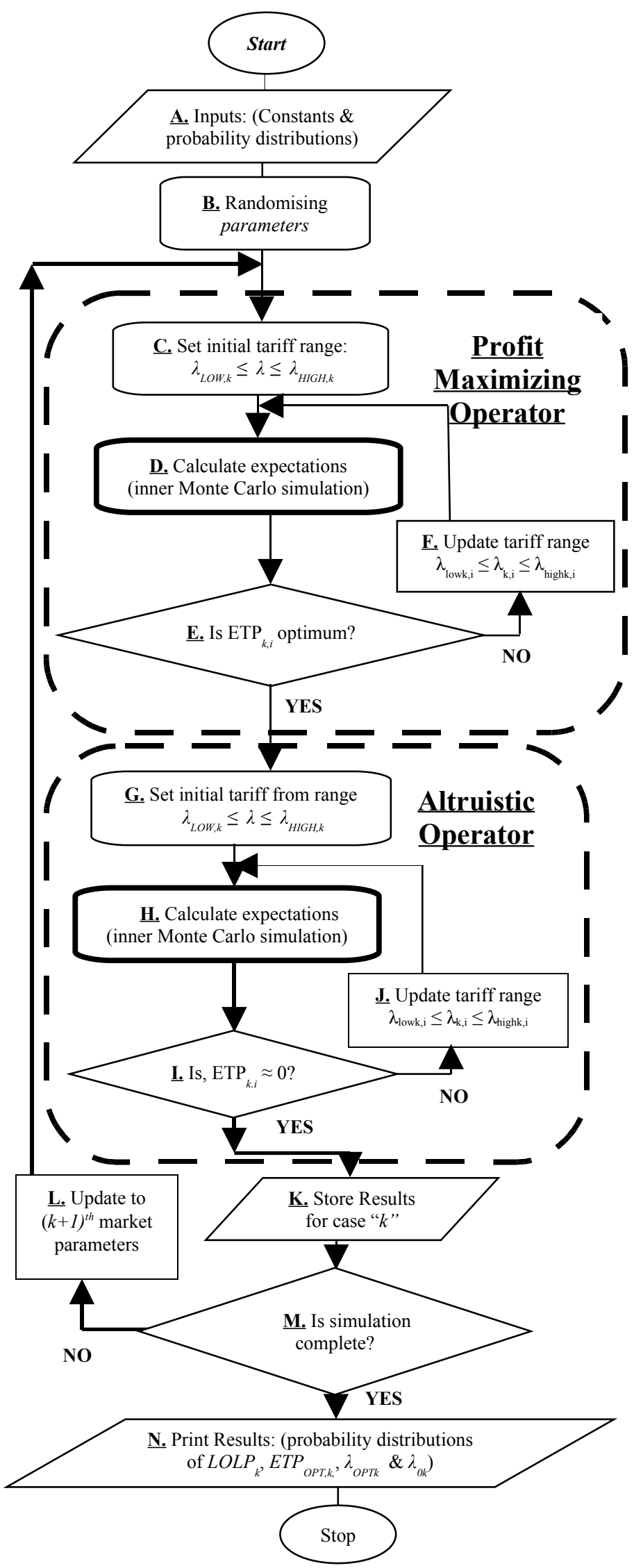

Fig. 4. Flow chart demonstrating the simulation concept 


\section{EXAMPLE}

\section{A. Inputs}

The methodology given in this paper has been tested on a fictitious rural power system. The power system can be supplied either by only diesel gensets $(G)$ or by a wind-diesel hybrid system $(H)$. Therefore there are two possible combinations of power supply for each type of power system operator: a profit maximizing operator operating a power system using either a diesel generator $(P M G)$ or a hybrid system $(P M H)$, and an altruistic operator operating a system using either a diesel genset $(A O G)$ or a hybrid system $(A O H)$. The inputs for the simulated example include the power system data summarized in table I, demand as represented by a relative load duration curve as given in the previous work [5], and the market parameters represented by the probability distributions. The demand factor, $\boldsymbol{\alpha}$ [US\$Cts $/ \mathrm{kWh}$ ], is assumed to be $\mathrm{N}(65.52,4.81)$ - distributed and the price sensitivity factor, $\boldsymbol{\beta}$ [US $\$ C$ ts.h $/ \mathrm{kWh}^{2}$ ], is assumed to be $\mathrm{U}(0.0812 \leq \beta \leq 0.1586)$ - distributed

Table I. Summary of Input data (Power Supply).

\begin{tabular}{|c|c|c|}
\hline Variable & Gensets & WT \\
\hline \hline Number of units & 1 & 1 \\
\hline Capacity $[\mathrm{kWh} / \mathrm{h}]$ & 250 & 60 \\
\hline Availability [\%] & 95 & 96 \\
\hline $\begin{array}{c}\text { Generation cost [US\$cts/kWh} \text { ] } \\
\text { based on fuel }\end{array}$ & 20 & - \\
\hline $\begin{array}{c}\text { Investment cost, } \mathrm{I}_{0}\left[\mathrm{x} 10^{3} \mathrm{US} \$\right]^{-} \\
\text {Expected life time (assumed to } \\
\text { be the credit period) [years] }\end{array}$ & 42 & 54 \\
\hline Assumed discount rate [\%] & 20 & 20 \\
\hline $\begin{array}{c}\text { Maintenance Costs [\% of } \\
\left.\text { annual, } \mathrm{I}_{0}\right]\end{array}$ & $15 \%$ & $1 \%$ \\
\hline
\end{tabular}

\section{B. Results}

The results from the simulation include probability distributions of: tariffs and loss of load probability for profit maximizing and altruistic system operators, differences in tariffs and loss of load probability for the two operators and the expected profit for the profit maximizing system operators. Ultimately, the results can be used to estimate and analyze the difference in tariff levels for the two types of operators operating the similar power systems. The results are presented both in graphical format using duration curves (figures 2 and 3 in the appendix) and in tabular format (table I and II). It should be noted that, the tariffs calculated in the simulation are sufficient to cover operation, maintenance and investment costs.

Since the profit maximizing operator supplies power at a higher tariff, the consumption will decrease, which means that the LOLP will become lower compared to the LOLP for an altruistic operator. Although the operation costs are lower with a hybrid power system, the profit maximizing operator can provide power almost at the same tariff when operating either a hybrid or a genset system. An altruistic operator can provide power at lower tariffs when operates a hybrid system than when operates only a genset system. This implies that the consumers or the society benefits more from an altruistic operator than from a profit maximizing operator. Therefore when a profit maximizing operator is making an investment, it is likely that the consumers may not have a direct benefit from the investment, whereas an altruistic operator passes on the benefit directly to the consumers.

Table II. Statistical Representation of tariff and LOLP.

\begin{tabular}{|c|c|c|c||}
\hline \multicolumn{4}{|c|}{ TARIFF ANALYSIS } \\
\hline \hline \multirow{2}{*}{$\begin{array}{c}\text { Power } \\
\text { System }\end{array}$} & $\begin{array}{c}\text { Type of } \\
\text { Operator }\end{array}$ & \multicolumn{2}{|c|}{$\begin{array}{c}\text { Statistical Values } \\
{[\text { US\$Cts/kWh] }}\end{array}$} \\
\cline { 3 - 4 } & & Mean & Standard deviation \\
\hline \hline \multirow{2}{*}{ Hybrid } & PMH & $\mathbf{5 0 . 8 4}$ & $\mathbf{3 . 3 4}$ \\
System & AOH & $\mathbf{3 3 . 4 2}$ & $\mathbf{1 . 1 5}$ \\
\hline Generator & PMG & $\mathbf{5 2 . 5 4}$ & $\mathbf{3 . 2 5}$ \\
\cline { 2 - 4 } Set (Genset) & AOG & $\mathbf{4 1 . 3 7}$ & $\mathbf{0 . 0 5}$ \\
\hline \multicolumn{4}{|c|}{ LOLP ANALYSIS } \\
\hline \hline Power & Type of & Values for Single System [\%] \\
\cline { 3 - 4 } System & Operator & Mean & Standard deviation \\
\hline \hline Hybrid & PMH & $\mathbf{3 . 9 3}$ & $\mathbf{0 . 6 4}$ \\
\cline { 2 - 4 } System & AOH & $\mathbf{1 1 . 7 3}$ & $\mathbf{7 . 5 0}$ \\
\hline Genset & PMG & $\mathbf{4 . 9 7}$ & $\mathbf{0 . 7 2}$ \\
\cline { 2 - 4 } & AOG & $\mathbf{7 . 1 1}$ & $\mathbf{5 . 9 0}$ \\
\hline
\end{tabular}

The differences between tariffs for altruistic and profit maximizing operators is larger with hybrid system than with the genset system (table II and graphs in figure 2). The average tariff levels for a hybrid system are less than the average tariff levels for a diesel genset. A profit maximizing operator operates at higher tariffs with more uncertainties (higher standard deviations) compared to the altruistic operator. This could be the fact that, since the profit maximizing operator is aiming at maximizing profits then must be very closely monitoring changes in consumers' price sensitivity. The tariffs for profit maximizing operators are set with uncertainties because they response quickly to consumers' price sensitivity (mainly to minimize chances of making financial losses). Although an altruistic operator closely monitor the consumers' price sensitivity, tariffs are set just to ensure economic sustainability of the power system and other social benefits.

Table III. Statistical representation of ETP for a profit maximising operator for the two power system options

Expected total profit for profit maximising operator when operating a hybrid system or only genset

\begin{tabular}{|c|c|c|c|}
\hline $\begin{array}{c}\text { Power } \\
\text { System }\end{array}$ & $\begin{array}{c}\text { Type of } \\
\text { Operator }\end{array}$ & $\begin{array}{c}\text { Mean } \\
{[U S \$ / h r]}\end{array}$ & $\begin{array}{c}\text { Standard deviation } \\
{[U S \$ / h r]}\end{array}$ \\
\hline Hybrid & PMH & $\mathbf{1 4 . 2 3}$ & $\mathbf{2 . 9 3}$ \\
\hline Genset & PMG & $\mathbf{5 . 9 2}$ & $\mathbf{2 . 6 6}$ \\
\hline
\end{tabular}


For a profit maximising operator it is advantageous to operate a hybrid system, though the tariff is set with uncertainties. The increased profit after the installation of a hybrid by a profit maximising operator can be attractive to investors and financial institutions. Because of the low tariffs charged and zero profits made by altruistic power system operators, their investments may not attract financial institutions.

\section{CONCLUSIONS}

Uncertainties in demand and supply of power systems are the motivation for using probability planning methods. This paper presents a procedure, based on Monte Carlo simulation, to estimate and investigate differences in tariffs and LOLP for the power system operated by either profit maximizing or altruistic operators. The market parameters in the model have been explicitly modeled as probability distributions. The methodology has been demonstrated on an example test system, showing how the results can be used as a basis for decision-making on tariff setting.

With reference to the example given in this paper, it has been realized that the consumers' price-sensitivity has a significant impact on the economic performance of isolated power systems. Availability and accessibility to perfect information about the market can help power system operators to closely monitor the consumers' price sensitivity. The changes in sensitivity prompt the profit maximizing operators to adjust the tariff accordingly in order to achieve the business objective (profit maximization). An altruistic operator is not quickly prompted by changes in sensitivity to have a significant adjustment in tariff; they only focus on the economic sustainability of the power system and benefits of the society. The two operators should choose a hybrid system for economic and social benefits. The profit maximizing operators should choose a hybrid system because the expected profit is higher (although with more uncertainty). Also altruistic operators should choose a hybrid system because they can charge lower tariffs and supply more energy (which is a social benefit).

The reliability of the system is higher when operated by the profit maximizing operator than when operated by an altruistic operator, i.e. LOLP $\mathrm{PM}_{\mathrm{PM}}<\mathrm{LOLP}_{\mathrm{AO}}$ respectively.

The methodology outlined could be useful to planners and researchers when investigating the possible range of tariffs and investigating risks involved when setting tariffs in an electricity market with uncertainties in both demand and supply. The risks involved in setting tariffs for the two operators (refer to the diagram, figure 1 and the standard deviations tables I and II) must be given special consideration by researchers and plan. In practice, the development of probability distributions of market parameters needs long term data to mimic and approximate the market behavior. Another interesting future research work is to investigate the impact of price camps and regulation on the profit maximizing operators.

\section{ACKNOWLEDGMENT}

The authors wish to extend their heartfelt appreciation and gratitude to Sida/SAREC and Makerere University through the Scholl of Graduate Studies for the financial support.

\section{REFERENCES}

[1] M. L. Katz and, H. S. Rosen, Microeconomics. McGrawHill, 1998

[2] J. Valenzuela, "A Probability Model for the Electricity Price Duration Curve under an Oligopoly Market", IEEE Transactions on Power Systems, Vol. 20. No. 3, August 2005, pp 1250 - 1256

[3] M. H. Morris, and \& M. L. Joyce, "How Marketers Evaluate Price Sensitivity", Industrial Marketing Management, vol. 17, pp. 169-176, 1988.

[4] M. G. Lijesen, "The real-time price elasticity of electricity", (article in press by the time of this publication) Energy Economics, August 2006

[5] A. Sendegeya, M. Amelin, L. Söder, E. Lugujjo, and I. P Da Silva, "Consumer price sensitivity impact on tariff level in isolated rural power systems", Published in Conference Proceedings in the $41^{\text {st }}$ International Universities Power Engineering Conference, (UPEC 2006)

[6] H. S Gupta, and D. R Lehmann., "Consumer price sensitivity and price thresholds", Journal of Retailing, 77, 435-456, 2001

[7] A. Kanudia, and P. Shukla, "Modeling of uncertainties and Price Elastic Demands in Energy-environment Planning for India", Int. J. Mgmt Science, Vol.26, No.3, pp. 409-423

[8] S. H Karaki. and R. B Chedid., "Probabilistic Production Costing of Diesel-Wind Energy Conversion Systems", IEEE Transactions on Energy Conversion, Vol.15,No.3, September 2003

[9] S. C. Chapra, and R. P. Canale, Numerical Methods for Engineers, forth edition, 2003 


\section{APPENDIX}
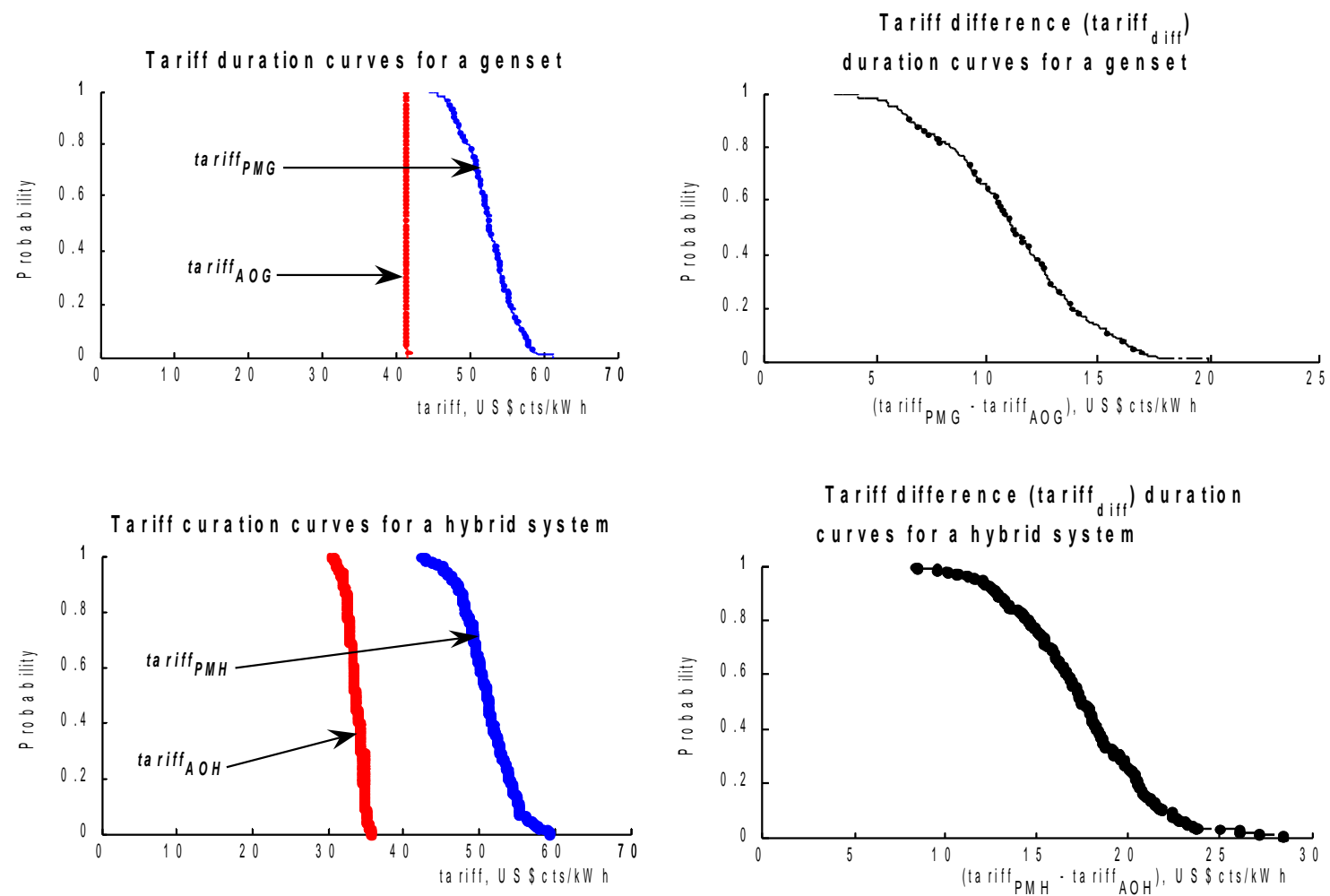

Fig. 2. Tariff duration curves showing the tariff distributions for both altruistic and profit maximising system operators
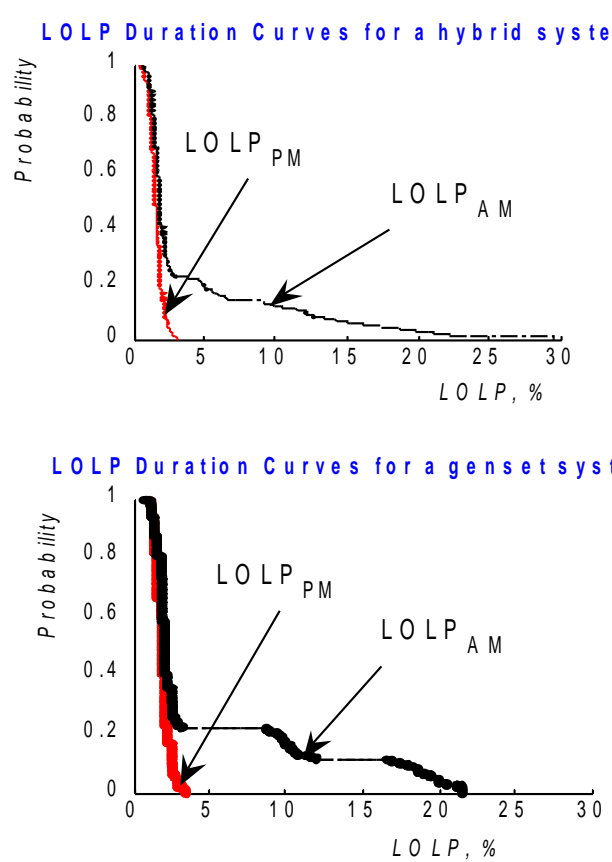
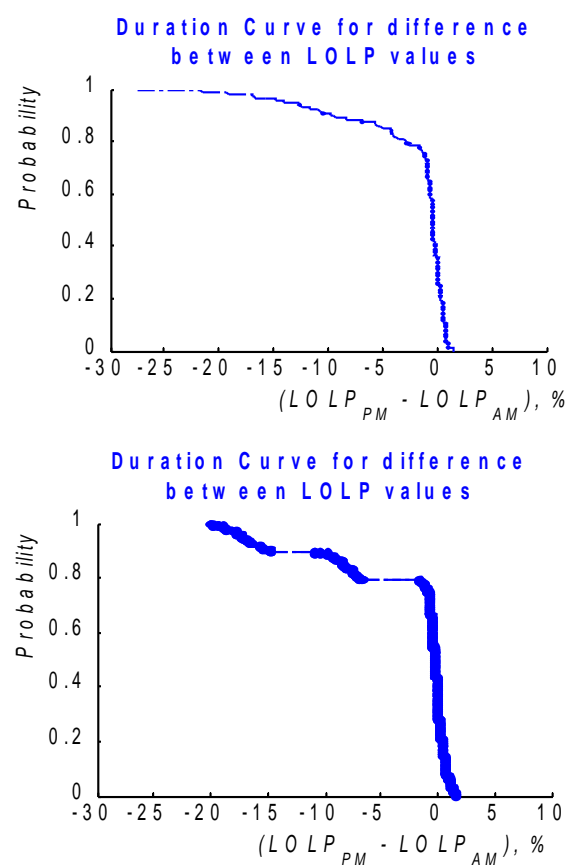

Fig. 3. LOLP duration curves showing the LOLP distributions for both altruistic and profit maximising system 